\title{
CONDITIONED MODIFICATION OF LOCOMOTION IN HERMISSENDA CRASSICORNIS: ANALYSIS OF TIME- DEPENDENT ASSOCIATIVE AND NONASSOCIATIVE COMPONENTS ${ }^{1}$
}

\author{
TERRY CROW
}

Department of Physiology, University of Pittsburgh School of Medicine, Pittsburgh, Pennsylvania 15261

Received April 19, 1983; Revised August 2, 1983; Accepted August 2, 1983

\begin{abstract}
The contribution of associative and nonassociative factors to the conditioned modification of phototactic behavior in Hermissenda was examined after varying the number of conditioning trials and the time between training and testing. Five or 10 conditioning trials did not produce significant changes in phototactic behavior when tested immediately after training. Both 5 and 10 conditioning trials resulted in significant short-term nonassociative changes in behavior (resembling sensitization) when the time between training and testing was 15 min or longer. Following 50 conditioning trials (single session training), nonassociative effects made the major contribution to the change in behavior when the post-training test interval was $30 \mathrm{~min}$. These nonassociative changes decremented during a 1-hr period following training. Significant associative effects were observed $45 \mathrm{~min}$ after 50 conditioning trials; however, significant associative effects were not observed when the same animals were tested $24 \mathrm{hr}$ after training. With 3 days of training (multiple session training-150 trials), associative effects were found $30 \mathrm{~min}$ after training and nonassociative effects again showed a rapid decrement during the 1-hr period following the end of training. The associative effects observed soon after training were persistent during the retention period and showed significant effects $24 \mathrm{hr}$ after training. These data indicate that (1) the behavioral effects found after single session training (5 and 10 trials) are nonassociative, and (2) these nonassociative effects do not increase significantly over the course of multiple session training. Since neural correlates of this conditioning have been identified in the primary sensory neurons of the conditioned stimulus pathway after both single session and multiple session training, it should be possible to examine the cellular mechanism responsible for the two different behavioral changes and to identify the mechanisms that can explain how this example of learning generates long-term associative changes in phototactic behavior.
\end{abstract}

Examples of associative learning have now been demonstrated in a number of molluscan preparations (Mpitsos and Davis, 1973; Gelperin, 1975; Mpitsos and Collins, 1975; Crow and Alkon, 1978; Crow and Offenbach, 1979, 1983; Walters et al., 1979, 1981; Davis et al., 1980; Sahley et al., 1981a, b; Carew et al., 1981, 1983). One of the advantages of these preparations is that the underlying mechanisms of associative learning can be examined under favorable cellular neurophysiological conditions. In addition, these preparations also provide an opportunity for investigating how different behavioral changes

\footnotetext{
${ }^{1}$ This work was supported by National Institutes of Health Grant HD15793. I thank Dr. J. H. Byrne for his comments on an earlier draft of the manuscript, Dr. Lewis Petrinovich for helpful discussions, Mark Bridge and Donna Haag for technical assistance with the experiments, and Barbara Plundeke for typing the manuscript.
}

are expressed by the same neural network. For example, the gill withdrawal reflex of Aplysia has been utilized for comparing mechanisms of nonassociative and associative learning (Pinsker et al., 1973; Carew et al., 1981). In Aplysia, associative learning seems to build upon the same mechanisms utilized for nonassociative learning (Hawkins et al., 1983; Walters and Byrne, 1983). The Pacific nudibranch, Hermissenda crassicornis, also exhibits both short-term nonassociative behavioral modifications resembling sensitization (Alkon, 1974) and long-term associative learning (Crow and Alkon, 1978). Since, in both Aplysia and Hermissenda, neural mechanisms of associative learning have been proposed, it becomes feasible to examine the possible generality of relationships between associative and nonassociative learning both at the behavioral and the cellular level.

Both short-term (Alkon, 1974) and long-term (Crow 
and Alkon, 1978) nonassociative changes in phototactic behavior have been reported previously for Hermissenda. However, the relationship between the number of training trials and the expression of associative effects has not been systematically explored. This is an important step for the cellular analysis of associative learning in Hermissenda, since it has recently been reported (Alkon, 1980; Farley and Alkon, 1982b) that analogues of conditioning and conditioning of the isolated nervous system produce cellular changes that are similar to those found after multiple session conditioning of intact animals (Crow and Alkon, 1980). If these correlates are causally linked to the behavior, then it follows that there should be a good correspondence between the neural correlates of the associative learning and behavioral data obtained from single session and multiple session training. The results of the present paper suggest that, in cellular studies using very few trials, one cannot be confident that the effects examined do not have a strong nonassociative component that must be controlled.

\section{Materials and Methods}

Two hundred eighty-three adult Hermissenda were used in the experiments. Animals were obtained from Sea Life Supply, Sand City, CA. The animals were maintained in an artificial seawater aquarium at $15^{\circ} \mathrm{C}$ on a 12-hr light, 12-hr dark cycle. Training and testing were conducted at approximately the same time in the light phase of the light-dark cycle.

Automated behavioral testing and training procedures have been described previously (Crow and Alkon, 1978; Tyndale and Crow, 1979) and thus will be described only briefly. The animals were trained and tested individually in seawater-filled glass tubes. The tubes were scrubbed and rinsed in seawater to remove mucus trails before collecting pretest and post-training measures of phototactic behavior. Animals were confined in the starting area of the tubes during training by small foam plugs inserted into an aperture $4 \mathrm{~cm}$ from the end of the glass tubes. For initial experiments, two measures of phototactic behavior were collected: (1) the initiation of locomotion, and (2) the time taken to locomote from the end of the tube into an illuminated area at the opposite end. The initiation of locomotion in response to the onset of light (defined as the start latency) was detected automatically by the triggering of an event marker when the Hermissenda moved between an infrared emitter and a phototransistor located at the starting end of the glass tube. Latencies for animals to locomote from the starting end of the tubes into the illuminated area at the opposite end of the tubes (defined as the finish latency) were measured by event markers triggered by the animals' movement between the overhead illuminator and photocells located beneath the ends of the tubes. For initial studies involving only a few training trials, base line pretests and post-training tests were collected for both measures of phototactic behavior. However, since start latencies account for most of the conditioned changes in behavior (Crow and Offenbach, 1979, 1983), and since the initial observations from animals in this study confirmed this, the latencies to initiate locomotion in the presence of illumination were used in the subsequent behavioral analysis. Animals that did not respond within a 25-min criterion period during the pretest measurements were not used in the experiments (10\% to $15 \%$ were discarded as nonresponders). Following pretest measurements, the animals were assigned to various training conditions. Since field-collected Hermissenda exhibit a considerable degree of variability in phototactic behavior (Crow and Harrigan, 1979), both paired and random controls for a given experimental condition were selected from the same shipment of animals.

Single session training. Animals used in these experiments received 5,10 , or 50 trials of light $(30 \mathrm{sec})$ paired with rotation $(95 \mathrm{rpm}$ ) with an average intertrial interval of $2.25 \mathrm{~min}$. The intensity of the white light used in training was $31 \times 10^{-3} \mathrm{~W} / \mathrm{cm}^{2}$. The intensity of the white test light was $28 \times 10^{-3} \mathrm{~W} / \mathrm{cm}^{2}$ as measured at the center of the turntable and $2.5 \times 10^{-4} \mathrm{~W} / \mathrm{cm}^{2}$ at the ends of the glass tubes where the animals were started. A delayed conditioning procedure was used: light preceded maximum rotation by $500 \mathrm{msec}$ and maximum rotation terminated with light offset. Random groups received light and rotation programmed on independent random schedules. Different groups of animals received 5 or 10 training trials and were tested either immediately after the last training trial (1 $\mathrm{min}$ ), or $15 \mathrm{~min}, 30 \mathrm{~min}, 45 \mathrm{~min}$, and 24 $\mathrm{hr}$ after training. Animals receiving 50 trials were tested $45 \mathrm{~min}$ after training. The Hermissenda were returned to their home cages in the aquarium during the various post-training retention periods with the exception of the 1 -min test. All animals were dark adapted in the testing apparatus $15 \mathrm{~min}$ before the onset of the test light following training. Retention test measurements were in the form of suppression ratios comparing post-training behavior with pretest scores. The ratios were expressed as $A / A+B$ where $A$ represented pretest scores and $B$ represented post-training scores. Ratios less than 0.50 indicated an increase in start latencies following conditioning.

Multiple session training. For these experiments, animals received 50 training trials and different groups of animals were tested 30,45 , or $60 \mathrm{~min}$ after the last training trial. Following the first retention test the same animals received 2 days of additional training, 50 trials each day, for two consecutive days. Following this additional training, the Hermissenda were tested again 30 , 45, or $60 \mathrm{~min}$ after the last training trial. As before, all animals were returned to their home cages during the retention interval and were dark adapted for $15 \mathrm{~min}$ before testing. Following the second post-training test, all paired and random control groups were tested $24 \mathrm{hr}$ after the end of behavioral training to assess long-term changes in behavior.

Statistical analysis. When appropriate, a two-way analysis of variance (treatments by trials) was used to assess overall main effects (Winer, 1962). Post hoc multiple comparisons involved Scheffé tests, and, in some cases, planned two-group comparisons involved $t$ tests for independent groups or correlated means (Winer, 1962). The justification and rationale for the different tests are described under "Results."

\section{Results}

Single session training (5 or 10 conditioning trials) produces only nonassociative effects. Since analogues of 
conditioning involving the presentation of several trials within a single session have produced cellular changes in B-type photoreceptors, the following experiments were conducted in order to test whether the effects of several conditioning trials are expressed by changes in the behavior of intact animals. Various amounts $(5,10$, and 50 trials) of single session training and different post-training test intervals ( $1 \mathrm{~min}, 15 \mathrm{~min}, 30 \mathrm{~min}, 45 \mathrm{~min}$, and 24 hr) were investigated since previous results (Alkon, 1974) indicated that single session training produced only nonassociative effects. Similar alterations of phototactic behavior of both paired and random groups indicate a nonassociative effect.

As an initial step in the analysis of the nonassociative contribution to the modification of phototactic behavior, Hermissenda received 5 or 10 conditioning trials and were then tested $1 \mathrm{~min}$ after the last training trial. Hermissenda that received $5(N=20)$ or 10 trials $(N=$ 20) of paired light and rotation and tested $1 \mathrm{~min}$ after the last training trial did not exhibit significant changes in behavior as compared to random controls $(N=20)$ (see Fig. $1 A$ ) or the base line pretest. In order to rule out the possibility that the animals in these samples were not capable of learning, the same animals were then given 3 days ( 150 trials) of additional training. As shown in Figure $1 B$, the behavioral tests of the same animals $(N=40)$ indicated that the failure to find significant
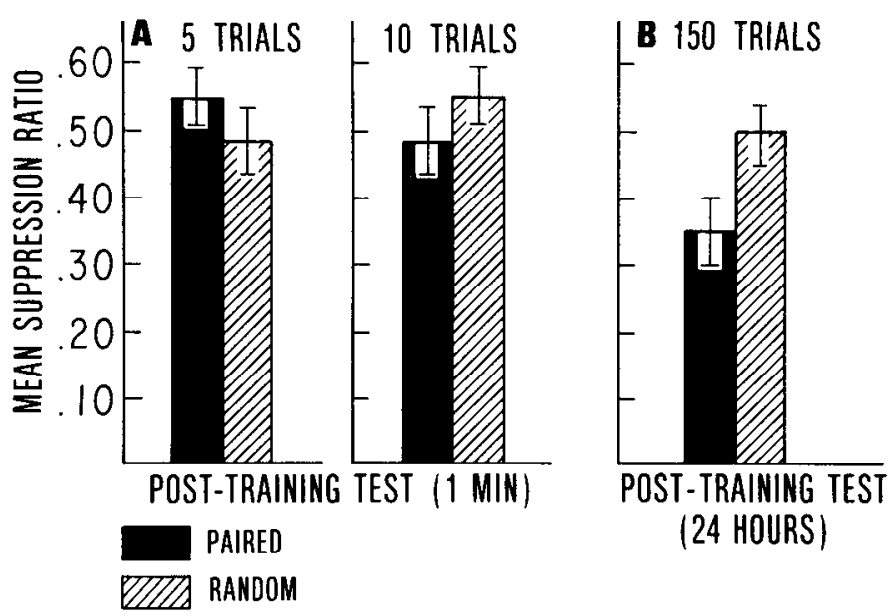

Figure 1. Absence of an effect of 5 and 10 conditioning trials on suppression of phototactic behavior. $A$, Post-training tests given 1 min after either $5(N=20)$ or $10(N=20)$ conditioning trials (solid bars) indicated that phototactic behavior (latency to locomote) did not significantly change relative to pretest latencies and random controls (striped bars) (total $N=20$ ). Behavioral measures following conditioning are expressed as mean suppression ratios in the form of $A / A+B$ where $A$ represents pretest latencies and $B$ represents post-training latencies. Thus, a suppression ratio of 0.50 means that phototaclic behavior is unchanged following conditioning. A suppression ratio greater than 0.50 means that the latency to locomote in the presence of light has decreased following conditioning, and a ratio less than 0.50 indicates an increase in the latency to locomote (behavioral suppression) in response to light following conditioning. $B$, The same animals $(N=40)$ show significant phototactic suppression as compared to random controls $(N=20) 24 \mathrm{hr}$ after 3 days of conditioning (150 trials) $(p<0.005)$. All pretest latencies and suppression ratios in this and subsequent figures are expressed as means \pm SEM. effects after 5 and 10 trials was not due to an inability of the animals to learn, because significant associative effects of training were observed $24 \mathrm{hr}$ after the end of 150 trials, comparing paired animals to random controls $(N=20)\left(t_{58}=3.06, p<0.005\right)$. Since the change in behavior following 5 or 10 trials may take some time in order to be expressed, additional experiments were conducted with longer post-training test intervals. The results of these experiments showed that, in contrast to the behavior of animals tested immediately after training, 5 or 10 conditioning trials produced significant changes in behavior when the animals were tested 15 or 30 min after conditioning (see Figs. 2 and $3 A$ ). For this experiment paired animals $(N=17)$ received five conditioning trials, random controls $(N=17)$ received five random presentations, and both groups were tested 15 min after the last trial. The animals were quickly removed from the tubes and then were placed back into the same tube and dark adapted for $15 \mathrm{~min}$ before testing. Animals tested under these conditions showed significant suppression of behavior when tested at $15 \mathrm{~min}$ as compared to tests conducted $24 \mathrm{hr}$ after five conditioning trials $\left(F_{1,32}=18.83, p<0.01\right)$ (Fig. 2). However, the effects were nonassociative since the paired group was not significantly different from the random control group. The results of retention tests for the same animals conducted $24 \mathrm{hr}$ after training indicated that the nonassociative effects following five trials were short-term, since the behavior of both random and paired groups was not significantly different from base line tests as indicated by suppression ratios close to 0.50 for both paired and random groups (see Fig. 2). The results of the next

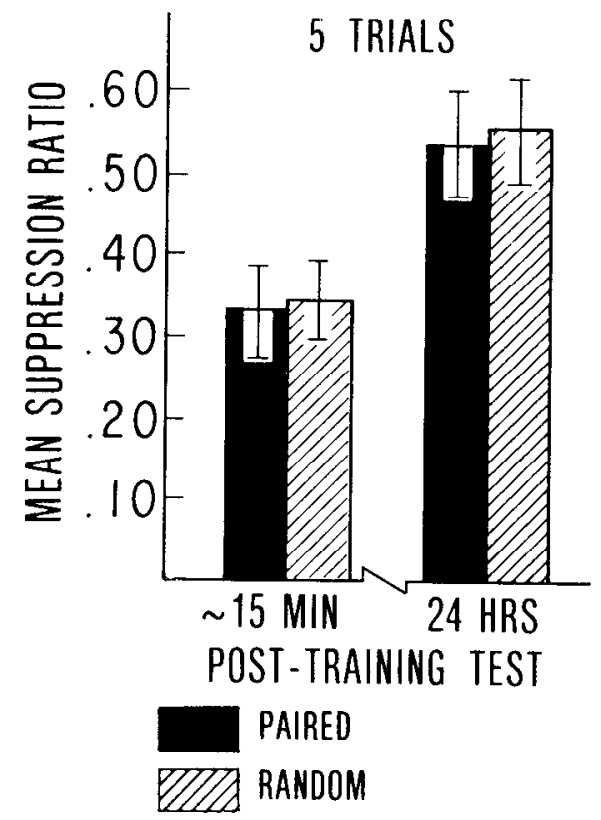

Figure 2. Time dependence of nonassociative effects of five conditioning trials on phototactic behavior. Both paired (solid bar) $(N=17)$ and random (striped bar $)(N=17)$ controls showed significant suppression following five conditioning trials when tested $15 \mathrm{~min}$ after conditioning. Ilowever, the nonassociative effect was short-lasting since both groups had returned to base line measures when tested $24 \mathrm{hr}$ after conditioning $(p<0.01)$. Thus, five trials produce only short-term nonassociative effects. 
experiment with a different group of animals showed that 10 conditioning trials produced significant changes in behavior only when the animals were tested $30 \mathrm{~min}$ after conditioning $\left(F_{1,36}=4.68 ; p<0.05\right)$. The changes in behavior produced by 10 conditioning trials were short-term since significant suppression of phototactic behavior was observed only for 30 -min post-training tests and not for tests conducted with a different group that received 10 conditioning trials and tested $45 \mathrm{~min}$ after training (Fig. $3 B$ ). However, the observed changes in behavior following 10 conditioning trials were again nonassociative since both paired and random groups were equally suppressed. There were no significant differences between the paired and random groups on any of the post-training tests following the independent experiments involving either 5 or 10 conditioning trials. In order to rule out the possibility that associative effects may be observed with longer post-training intervals, the same animals were again tested $24 \mathrm{hr}$ after training. The results of the 24-hr retention test indicated that, indeed, the nonassociative modification of behavior found 30 min after 10 conditioning trials was short-term, since retesting the same animals $24 \mathrm{hr}$ after training revealed no significant differences between start latencies compared to pretest scores for either paired $(N=10)$ or random controls $(N=10)$ (Fig. $3 A)$. Retention tests conducted $24 \mathrm{hr}$ after training for the group originally tested 45 min after 10 trials again showed no significant differences between paired or random control groups (see Fig. $3 B$ ). These results indicate that 5 or 10 conditioning trials produce only nonassociative effects on phototactic behavior. These changes take time to build up, since they are not observed immediately after training and then

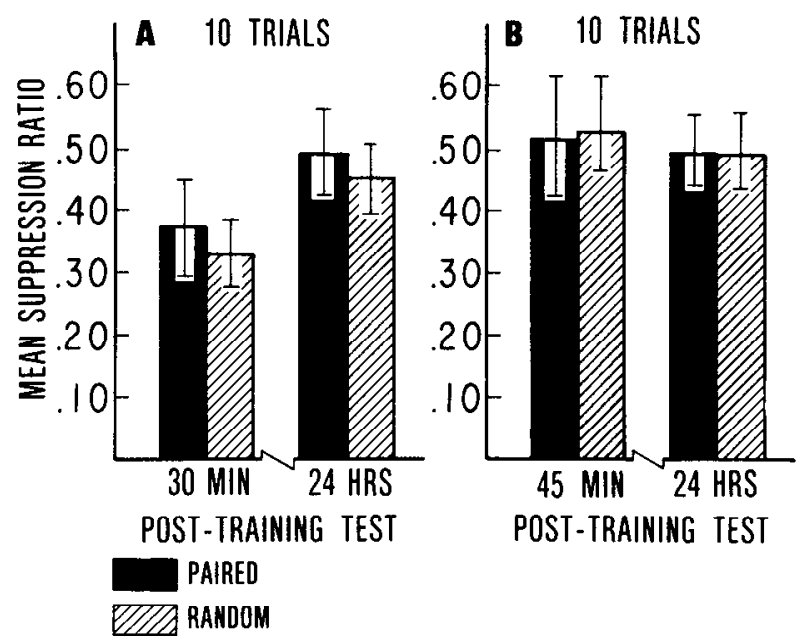

Figure 3. Time dependence of nonassociative effects produced by 10 conditioning trials. $A$, Both paired (solid bar) ( $N$ $=10)$ and random (striped bar) $(N=10)$ control groups show significant behavioral suppression when tested 30 min after 10 conditioning trials $(p<0.05)$. However, the changes are shortterm since tests of the same animals $24 \mathrm{hr}$ after conditioning did not reveal significant suppression. $B$, Both paired $(N=10)$ and random $(N=10)$ control groups did not show significant behavioral suppression following 10 conditioning trials when tested $45 \mathrm{~min}$ and $24 \mathrm{hr}$ after conditioning. Thus, 10 trials produce only short-term nonassociative effects on phototactic behavior. decrement over a $1-\mathrm{hr}$ period following the termination of training.

Increased trials in a single session can produce transient associative effects. Since the results of varying the interval between conditioning and testing revealed nonassociative changes in behavior, additional experiments consisting of a greater number of trials were conducted in order to assess any possible associative effects produced in one conditioning session. In this experiment paired groups $(N=19)$ received 50 conditioning trials and random controls $(N=10)$ received random presentations of the stimuli. Both groups were then tested 45 min after training. Because of the unequal sample sizes between paired and random groups, selected comparisons were made with $t$ tests for independent groups and $t$ tests for correlated means to facilitate data analysis. The $45-\mathrm{min}$ post-training test interval was selected on the basis of the results from studies described in the section on multiple session training (see below and Fig. 6). The results of this experiment indicated that associative effects can be produced in a single training session. Significant differences between paired and random groups were found after one 50-trial session when the animals were tested 45 min later $\left(t_{27}=2.67, p<0.01\right)$ (Fig. 4). However, the associative effect was short-term since the paired group had returned to base line when examined $24 \mathrm{hr}$ after training, thus showing significant behavioral recovery $\left(t_{18}=4.79, p<0.005\right.$ ) (see Fig. 4 ).

Multiple session training. The previous results indicated that single session training with 5 or 10 conditioning trials produces strong short-lasting nonassociative changes in phototactic behavior. However, a short-term

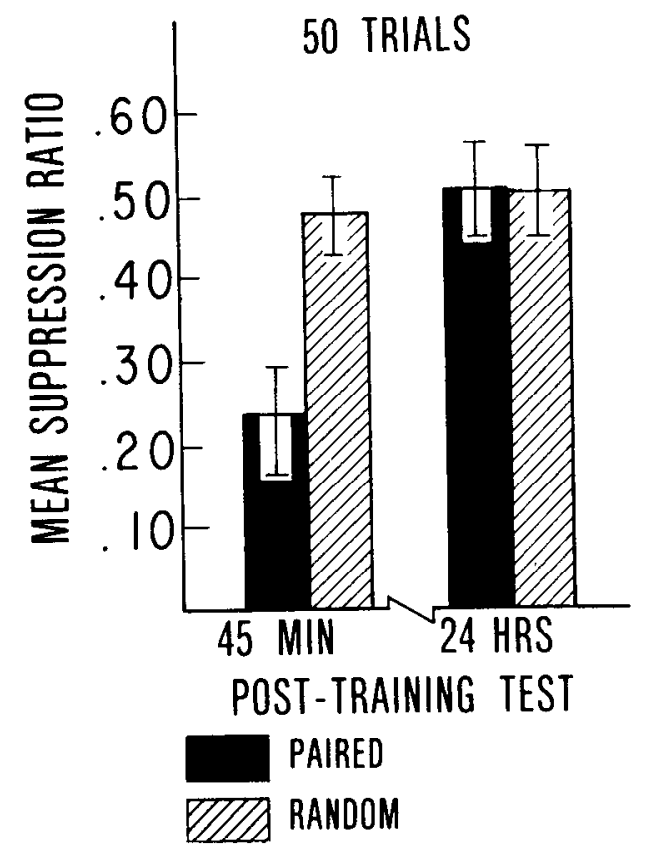

Figure 4. Transient associative effects are produced in a single training session. Fifty conditioning trials result in significant differences in phototactic suppression between the paired groups (solid bars) $(N=19)$ and random controls (striped bars) $(N=10)$ when tested 45 min after training $(p<$ 0.01 ). However, the associative effects were short-term since both paired and random groups had returned to base line levels when tested $24 \mathrm{hr}$ after training. 
associative component of phototactic behavior was produced in a single training session of 50 conditioning trials. Therefore, the next experiments examined the time course of associative and nonassociative components of phototactic suppression produced by both single and multiple training sessions. In the first experiment, paired $(N=20)$ and random control animals $(N=20)$ received 50 conditioning trials in one training session and were then tested $30 \mathrm{~min}$ after training (Fig. 5A). Following the first test the same animals received an additional 100 trials over a 2 -day training period in multiple training sessions and were again tested $30 \mathrm{~min}$ after training. All animals were then tested $24 \mathrm{hr}$ after multiple session training (150 trials) to assess long-term changes in behavior (Fig. $5 B$ ). This procedure provides the opportunity to assess the contribution of nonassociative and associative effects to phototactic suppression in the same animals and at the same post-training retention period following both single session and multiple session training. Multiple session training produced significant effects which were reflected by a decrease in overall behavioral suppression for both experimental and random control groups analyzed together $\left(F_{2,76}=3.7, p<\right.$ 0.05 ). These results could be accounted for by the contribution to phototactic suppression of the substantial, although transient, nonassociative effects produced by single session training and extinction produced by posttraining tests following multiple session training. An analysis of the paired and random controls revealed that only nonassociative effects were detected $30 \mathrm{~min}$ after single session training (50 trials) (Fig. 5A). In contrast to the results of single session training, associative effects
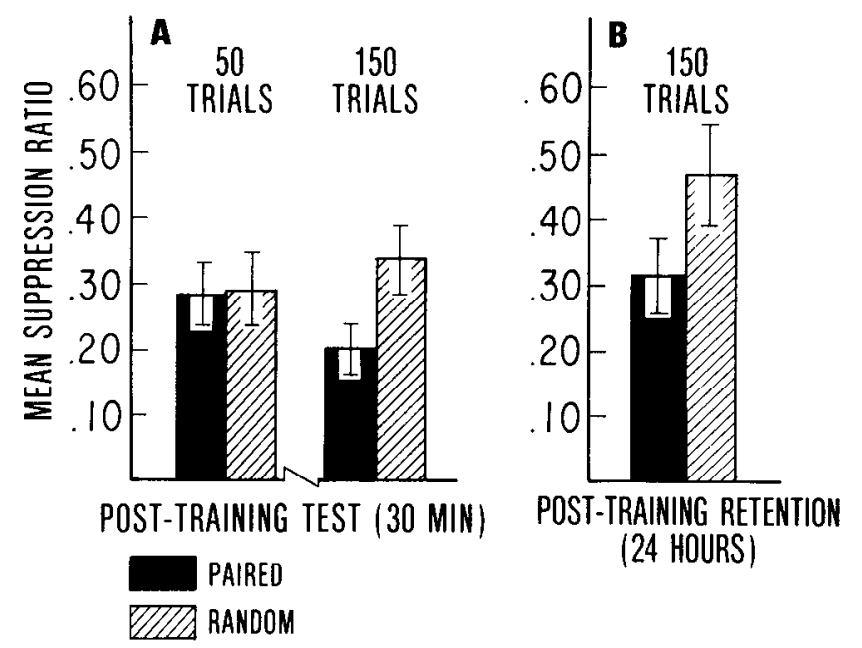

Figure 5. Comparison of post-training retention (30 $\mathrm{min})$ following single session (50 trials) and multiple session (150 trials) training. $A$, Both paired (solid bars) $(N=20)$ and random control groups (striped bars) $(N=20)$ showed nonassociative suppression when tested $30 \mathrm{~min}$ after single session training. Following multiple session training, significant $(p<0.05)$ associative effects were observed $30 \mathrm{~min}$ after training. $B$, The associative effects produced by multiple session training are long-term since the paired group was significantly different from random controls when tested $24 \mathrm{hr}$ after training ( $p<$ 0.025 ). Thus only nonassociative effects are detected $30 \mathrm{~min}$ after single session training, whereas associative effects are found $30 \mathrm{~min}$ after multiple session training. were observed 30 min after multiple session training $\left(t_{38}\right.$ $=1.86, p<0.05$ ) (Fig. 5A). The associative effects observed following multiple session training are longlasting since the paired group was significantly different from the random controls which had returned to base line levels $24 \mathrm{hr}$ after training $\left(t_{38}=2.13, p<0.025\right)$ (Fig. $5 B$ ). These results indicate that post-training tests conducted $30 \mathrm{~min}$ after training detect significant associative effects only after multiple session training (150 conditioning trials).

Since the previous results indicated that only nonassociative effects were detected when the animals were tested 30 min after single session training, additional experiments involving different groups of animals were conducted to investigate the relative associative and nonassociative contributions produced by single and multiple session training when tested $45 \mathrm{~min}$ after training. These experiments examined both associative and nonassociative effects $45 \mathrm{~min}$ after single session (50 trials) and multiple session training (150 trials) for paired groups $(N=20)$ and random controls $(N=20)$. The experiments employed the same protocol as those described above and in Figure 5, except that the post-training test occurred at $45 \mathrm{~min}$ rather than at $30 \mathrm{~min}$. These results indicate that both single and multiple session training produce associative effects (Fig. 6). Significant overall associative effects were produced both after single and after multiple session training when tested $45 \mathrm{~min}$ after training $\left(F_{1,38}=10.42, p<0.01\right)$. This behavioral effect was expressed by significant differences between paired and random groups after one session (Scheffé test, $p<$ 0.01 ) and multiple session training (Scheffé test, $p<$ 0.01 ). The significant decrease in overall behavioral suppression with increased training for both groups taken collectively $\left(F_{2,76}=3.47, p<0.05\right)$ may reflect the contribution of the early transient nonassociative components of behavioral suppression found after single
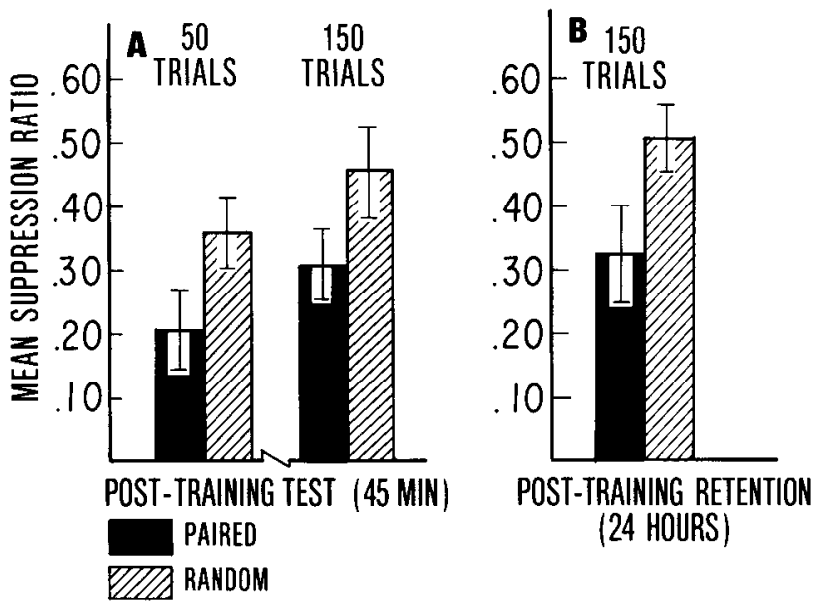

Figure 6. Comparison of post-training retention (15 $\mathrm{min})$ following single session (50 trials) and multiple session (150 trials) training. $A$, Significant associative effects are found 45 min after both single and multiple session training $(p<0.01)$. $B$, The associative effects are long-term since the paired group was significantly different from random controls when tested $24 \mathrm{hr}$ after training $(p<0.01)$. Thus, an associative effect can be detected after single session training when tested at $45 \mathrm{~min}$ but not at $30 \mathrm{~min}$ (cf. Fig. 5A). 
session training (see Fig. $7 A$ ). The associative effects produced by multiple session training are long-lasting as shown by the significant suppression of the paired group when tested $24 \mathrm{hr}$ after training $(p<0.01)$.

The previous experiment indicated that single session training produces an associative effect that could be detected when the animals were tested $45 \mathrm{~min}$ after training. In order to investigate the time course of the single session associative effect, an additional experiment was conducted in which the animals were tested 60 min after single session and multiple session training (Fig. 7). In this experiment paired $(N=20)$ and random control ( $N=20)$ groups received single session (50 trials) and multiple session (150 trials) training and were then tested $60 \mathrm{~min}$ after training. Significant associative effects were produced by multiple session training $\left(F_{1,38}=\right.$ $16.36, p<0.01)$. However, the associative effect produced by single session training is short-lasting since the paired group was not different from the random controls when tested $60 \mathrm{~min}$ after conditioning (Fig. $7 \mathrm{~A}$ ). In contrast to these results, multiple session training produced significant associative effects when tested both at $60 \mathrm{~min}$ and at $24 \mathrm{hr}$ after training $(p<0.01)$ (Fig. $7, A$ and $B$ ). These results indicate that the associative effects observed in one session (50 trials) are indeed short-term (Fig. $7 \mathrm{~A}$ ) since they are only observed when animals are tested 45 min after training and are not present when animals are tested at $60 \mathrm{~min}$. Taken collectively, these experiments show that there are clear differences between single session and multiple session training with regard to the relative magnitude and time course of associative and nonassociative effects. Single session

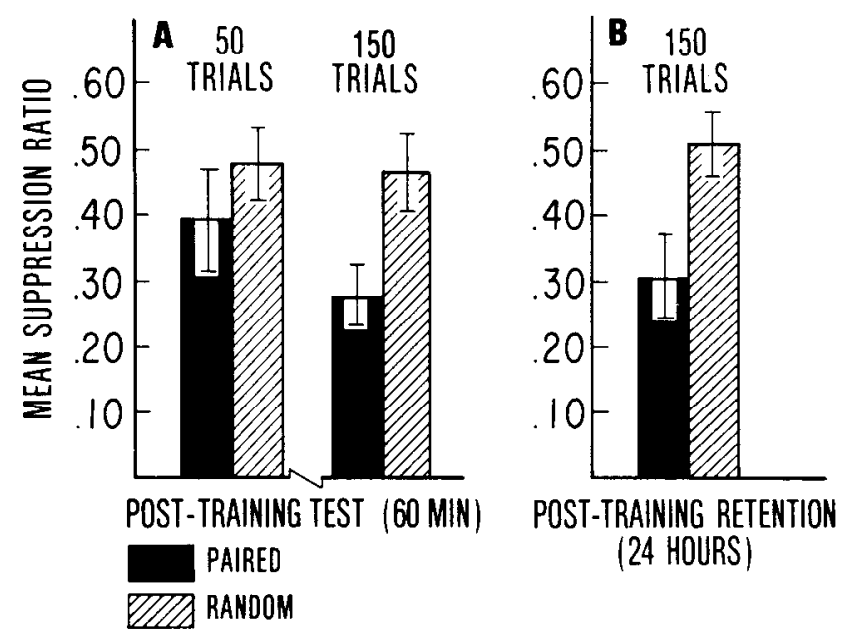

Figure 7. Comparison of post-training retention (60 min) following single session (50 trials) and multiple session (150 trials) training. $A$, The associative effect produced by single session training is short-term since the paired $(N=20)$ and random $(N=20)$ controls were not significantly different from each other when tested $60 \mathrm{~min}$ after one conditioning session (50 trials). However, significant associative effects were detected 60 min after multiple session training (150 trials) $(p<$ 0.01 ). $B$, The associative effects after multiple session training are long-term since the paired group was significantly different from random controls when tested $24 \mathrm{hr}$ after training ( $p<$ 0.01 ). Thus, single session training (50 trials) produces both short-term associative and nonassociative effects, whereas mulliple session training produces a long-lasting associative effect. training (50 trials) has two main effects: (1) a strong nonassociative effect that is short-term and (2) a shortlasting associative effect. These nonassociative and associative effects appear to have different time courses. Multiple session training has two main effects: (1) a strong associative effect that is long-term and (2) a weak nonassociative effect that is short-term and does not increase during training.

\section{Discussion}

Short-term nonassociative components of phototactic behavior. The primary goal of this paper was to examine the relative contribution of nonassociative and associative effects following conditioning in Hermissenda. The results indicate that very few training trials produce purely nonassociative effects, specifically, the modification of both the initiation of locomotion and the latency to move into an illuminated area after 5 and 10 conditioning trials is due to only nonassociative factors (see Figs. 2 and 3). The failure to find significant associative phototactic suppression after 5 or 10 trials was not due to the animals' inability to learn since the same animals exhibited significant associative effects when they were subsequently trained for 3 days and tested $24 \mathrm{hr}$ after training. The long-term associative changes found in the present study after 3 days of training (150 trials) are consistent with previously published observations of associative learning in Hermissenda (Crow and Alkon, 1978; Crow and Harrigan, 1979; Crow and Offenbach, $1979,1983)$. In addition, the finding of significant nonassociative changes in phototactic behavior resulting from multiple session training with light and rotation (see Fig. 5) is consistent with previous results (Crow and Alkon, 1978; Crow and Harrigan, 1979). Thus, the findings of this study support the hypothesis that short-term nonassociative effects are time dependent because significant suppression of behavior was not found immediately after training $(1 \mathrm{~min})$ (e.g., Fig. 1). However, significant nonassociative changes were observed $15 \mathrm{~min}$ and 30 min after training (Figs. 2 and 3). These nonassociative changes in behavior decrement rapidly, since significant differences were not observed when tests were conducted with a different group 45 min after training (see Fig. 3B).

The results of the single session training (5 and 10 trials) presented here are inconsistent, however, with a recent report of Farley and Alkon (1982b) in which they found significant short-term associative effects after five training trials in an intact preparation. The procedures used in their study and in the present one were the same; moreover, the failure to find an associative effect after single session training in this study was not due to an unrepresentative sample and/or bias since three independent replications from three different animal shipments yielded similar results. In addition, these behavioral experiments were, as before, automated and were conducted using standard blind procedures.

Nonassociative effects found soon after conditioning in this study are in general similar to sensitization effects found in Aplysia (Carew et al., 1981). Namely, there is a delayed development of the nonassociative component of the behavioral modification. However, in the present 
study the nonassociative effects observed after 10 trials decrement faster (observed at $30 \mathrm{~min}$ but not at $45 \mathrm{~min}$ after conditioning) than sensitization of the gill withdrawal reflex found after 1 or 15 trials, which increases systematically over a 1 -hr period following conditioning (see Carew et al., 1981). In differential classical conditioning of the siphon withdrawal reflex of Aplysia, the nonassociative effects increase in a systematic way by increasing the number of conditioning trials (Carew et al., 1983). The nonassociative effects observed in the present study of phototactic behavior do not increase with increases in the number of conditioning trials. In fact, nonassociative effects are more pronounced at the end of 50 trials as compared to 150 trials with short posttraining test intervals (see Figs. 5 to 7). Since the nonassociative and associative effects observed in the present study have different time courses, it may indicate that the underlying mechanisms are independent; i.e., the mechanism for the associative effect is not an elaboration of the nonassociative mechanism. However, it is interesting to note that the nonassociative component is always behaviorally expressed before the associative contribution to phototactic suppression. Therefore, it is possible that the mechanism of conditioning may indeed build upon the nonassociative mechanism as has been suggested for Aplysia (Carew et al., 1981; Hawkins et al., 1983; Walters and Byrne, 1983).

Long-term associative and nonassociative effects. Multiple session training (three training sessions) revealed that the nonassociative contributions to the modification of behavior reach asymptote after 50 trials since random controls did not exhibit significant increases in phototactic suppression with more training (Figs. 5 to 7 ). The rapid decrement of the nonassociative response is similar after both single and multiple session training. In contrast to the behavior of the random control, which reflects the nonassociative contribution to phototactic suppression, the paired group was significantly different after 150 trials as compared to 50 trials using a posttraining test interval of 30 or $60 \mathrm{~min}$. However, significant associative effects were observed after 50 trials when the post-training interval was $45 \mathrm{~min}$ (see Fig. $6 \mathrm{~A}$ ). The finding of both significant associative effects and nonassociative effects after multiple session training (150 trials) is in agreement with the initial examination of conditioning in Hermissenda (Crow and Alkon, 1978). In this initial study, after 3 days of training, all control groups, when tested immediately after training, showed significant changes in behavior relative to their base line measures, although the paired group showed significantly greater changes than did the various control groups. A similar outcome was observed in a conditioning study of laboratory-reared Hermissenda (Crow and Harrigan, 1979). However, recently it has been suggested that associative effects are not present immediately after 150 trials of training (Farley and Alkon, 1982a). This conclusion may be the result of the methods used to assess associative effects rather than the result of an absence of an associative effect. In the original study (Crow and Alkon, 1978), when animals were tested immediately after the conclusion of 3 days of training, a maximum latency (cutoff score) of $180 \mathrm{~min}$ was employed. In the study by Farley and Alkon (1982a), a cutoff score of only 30 min was used. Using such a low cutoff score would probably not have resolved differences between experimental and random control groups since many animals would not have initiated locomotion within the $30-\mathrm{min}$ criterion period. Thus, this study simply did not wait long enough to detect the associative effects that had been reported previously.

Certainly the nonassociative effects found immediately after training must be considered in interpreting cellular studies of conditioning in Hermissenda. However, the present study shows that nonassociative effects make a greater contribution to the change in phototactic behavior following training, with only a few trials, which is consistent with the earlier observation by Alkon (1974) of an effect resembling sensitization after single session training (as opposed to multiple session training) using a different training procedure. In the present study, the effects after 10 training trials were nonassociative, and even after 50 trials significant associative effects were not observed until $45 \mathrm{~min}$ after training. In contrast to these results, 3 days of training results in significant associative effects that were observed $30 \mathrm{~min}$ after training. Consequently, the amount of time that must intervene between the end of training and the start of testing in order for associative specificity to be exhibited depends on the amount of original training.

Cellular studies of neural correlates in B-photoreceptors. Given the time dependence of the associative effect described above, it is important to consider that neurophysiological and biochemical studies designed to examine correlates of associative learning be conducted using animals trained with an appropriate number of trials and tested at a time when the associative effects are expressed. Previous cellular neurophysiological and biochemical studies of conditioning were initiated relatively soon after the termination of 3 days of training (Crow and Alkon, 1980; Neary et al., 1982). The present findings indicate that associative effects are observed within $30 \mathrm{~min}$ of training. Since, in the cellular studies, most of the measurements of cellular changes were collected from $1 \mathrm{hr}$ up to several hours following the conclusion of training, the cellular correlates are likely to accurately reflect associative consequences of paired light and rotation.

In contrast to the correlates obtained following multiple session training, an important question still remains concerning the relationship between correlates of conditioning and behavior observed after single session (5 to 10 trials) training (Alkon, 1980; Farley and Alkon, $1982 \mathrm{~b}$ ), because the present data indicate that any such correlates would reflect nonassociative rather than associative effects. Previously, it has been found that stimulation of the isolated nervous system with only two trials of light paired with rotation (Alkon, 1980) produces a cumulative depolarization of the type B photoreceptor that is similar in magnitude to the tonic dark-adapted depolarization found after 3 days of training (150 trials) (Crow and Alkon, 1980). However, since two training trials would not be expected to produce any associative behavioral changes, it would be surprising if such correlates were causally related to the behavioral modification. 
In addition, there is recent evidence suggesting that a transient outward potassium current known as $I_{A}$ can be suppressed by only a few pairings of light with depolarizing command potentials under voltage clamp (Alkon et al., 1982b). It was previously reported that this current $\left(I_{A}\right)$ is also reduced after multiple session training conditions and, further, that this reduction in $I_{A}$ can account at least in part for the decrease in the steady-state dark conductance of B-type photoreceptors of conditioned Hermissenda (Alkon et al., 1982a; Shoukimas and Alkon, 1983). Therefore, taken collectively, these data suggest that the basic mechanism for both acquisition and retention of conditioning found in the photoreceptors may be the same for both single session and multiple session training. However, the results of the present study indicate that neither associative nor nonassociative changes in behavior are found immediately after 5 or 10 conditioning trials. Furthermore, with longer post-training intervals, the behavioral changes after 10 trials are due only to nonassociative factors. This lack of correspondence between the cellular correlates of conditioning and behavior produced by single session training is currently under investigation. The possibility exists that a different mechanism may account for the long-term modification of phototactic behavior than that proposed for single session training. Indeed, changes in the adaptation properties of the type $B$ photoreceptors of conditioned Hermissenda trained with 150 trials have been found that cannot be mimicked by blocking $I_{A}$ (Crow, 1982, 1983). This suggests the possibility that a number of different cellular changes may be produced in B-photoreceptors by the conditioning procedure and that these different types of changes may account for the associative and nonassociative aspects of the behavior.

\section{References}

Alkon, D. L. (1974) Associative training of Hermissenda. J. Gen. Physiol. 64: 70-84.

Alkon, D. L. (1980) Membrane depolarization accumulates during acquisition of an associative behavioral charge. Science 210: 1375-1376.

Alkon, D. L., I. Lederhendler, and J. J. Shoukimas (1982a) Primary changes of membrane currents during retention of associative learning. Science 215: 693-695.

Alkon, D. L., J. J. Shoukimas, and E. Heldman (1982b) Calcium-mediated decrease of a voltage-dependant potassium current. Biophys. J. 40: 245-250.

Carew, T. J., E. T. Walters, and E. R. Kandel (1981) Classical conditioning in a simple withdrawal reflex in Aplysia californica. J. Neurosci. 1: 1426-1437.

Carew, T. J., R. D. Hawkins, and E. R. Kandel (1983) Differential classical conditioning of a defensive withdrawal reflex in Aplysia californica. Science 219: 397-400.

Crow, T. (1982) Sensory neuronal correlates of associative learning in Hermissenda. Soc. Neurosci. Abstr 8: 824.

Crow, T. (1983) Conditioned modification of sensory adaptation in Hermissenda photoreceptors. Fed. Proc. 42: 1346.

Crow, T., and D. L. Alkon (1978) Retention of an associative behavioral change in Hermissenda. Science 201: 1239-1241.

Crow, T., and D. L. Alkon (1980) Associative behavioral modification in Hermissenda: Cellular correlates. Science 209: 412-414.
Crow, T., and J. F. Harrigan (1979) Reduced behavioral variability in laboratory-reared Hermissenda crassicornis. Eschscholtz, 1831 (Opisthobranchia:nudibranchia). Brain Res. 173: $179-184$.

Crow, T., and N. Offenbach (1979) Response specificity following behavioral training in the nudibranch mollusk Hermissenda crassicornis. Biol. Bull. 157: 364 .

Crow, T., and N. Offenbach (1983) Modification of the initiation of locomotion in Hermissenda: Behavioral analysis. Brain Res. 271: 301-310.

Davis, W. J., J. Villet, D. Lee, M. Rigler, R. Gillette, and E. Prince (1980) Selective and differential avoidance learning in the feeding and withdrawal behavior of Pleurobranchaea californica. J. Comp. Physiol. A Sens. Neural Behav. Physiol. 138: $157-165$.

Farley, J., and D. L. Alkon (1982a) Associative neural and behavioral change in Hermissenda: Consequences of nervous system orientation for light and pairing specificity. J. Neurophysiol. 48: 785-807.

Farley, J., and D. L. Alkon (1982b) Cumulative cellular depolarization and short term associative conditioning in $\mathrm{Her}$ missenda. Soc. Neurosci. Abstr. 8: 825.

Gelperin, A. (1975) Rapid food-aversion learning by a terrestrial mollusk. Science 189: 567-570.

Hawkins, R. D., T. W. Abrams, T. J. Carew, and E. R. Kandel (1983) A cellular mechanism of classical conditioning in Aplysia: Activity-dependent amplification of presynaptic facilitation. Science 219: 400-405.

Mpitsos, G. J., and S. D. Collins (1975) Learning: Rapid aversive conditioning in the gastropod mollusk Pleurobranchaea. Science 188: 954-957.

Mpitsos, G. J., and W. J. Davis (1973) Learning: Classical and avoidance conditioning in the mollusk Pleurobranchaea. Science 180: $317-320$.

Neary, J. T., T. Crow, and D. L. Alkon (1982) Change in a specific phosphoprotein band following associative learning in Hermissenda. Nature 293: 658-660.

Pinsker, H. M., W. A. Hening, T. J. Carew, and E. R. Kandel (1973) Long-term sensitization of a defensive withdrawal reflex in Aplysia. Science 182: 1039-1042.

Sahley, C., A. Gelperin, and J. W. Rudy (1981a) One-trial associative learning in a terrestrial mollusk. Proc. Natl. Acad. Sci. U. S. A. 78: 640-642.

Sahley, C., J. W. Rudy, and A. Gelperin (1981b) An analysis of associative learning in the terrestrial mollusc Limax maximus. I. Higher-order conditioning, blocking, and a transient US-preexposure effect. J. Comp. Physiol. A Sens. Neurol. Behav. Physiol. 144: 1-8.

Shoukimas, J. J., and D. L. Alkon (1983) Effect of voltagedependent $\mathrm{K}^{+}$conductances upon the initial generator response in B-photoreceptor of H. crassicornis. Biophys. J. 41: 37a.

Tyndale, C. L., and T. Crow (1979) An IC control unit for generating random and nonrandom events. IEEE Trans. Biomed. Eng. 26: 649-655.

Walters, E. T., and J. H. Byrne (1983) Associative conditioning of single sensory neurons suggest a cellular mechanism for learning. Science 219: 405-408.

Walters, E. T., T. J. Carew, and E. R. Kandel (1979) Classical conditioning in Aplysia californica. Proc. Natl. Acad. Sci. U. S. A. 76: 6675-6679.

Walters, E. T., T. J. Carew, and E. R. Kandel (1981) Associative learning in Aplysia: Evidence for conditioned fear in an invertebrate. Science 211: 504-506.

Winer, B. J. (1962) Statistical Principles in Experimental Design. McGraw-Hill Book Co., New York. 